\title{
Estimating the features of nervous processes among medical students as one of the main factors influencing labor productivity
}

\author{
Igor Skiba ${ }^{*}$, Igor Konovalov ${ }^{2}$, Yulia Emelyanova ${ }^{2}$, Valentina Kosulina ${ }^{2}$, Elza \\ Akhmetshina ${ }^{3}$ \\ ${ }^{1}$ Kazan State Medical University, Physical upbringing and health department, 420012, Kazan, Russia \\ ${ }^{2}$ Volga Region State Academy of Physical Culture, Sports and Tourism, 420010, Kazan, Russia \\ ${ }^{3}$ Kazan Innovative University named after V.G. Timiryasov, 423822, Naberezhnye Chelny, Russia
}

\begin{abstract}
The article considers the results of studying nervous processes in medical students. They influence labor functions productivity in the future labor activity. Testing was held by means of hardware and software complex (HSC) "NS-PsychoTest". It includes several specialized tests for the experimental study of nervous system and a person's psychological part. The main features of respondents' nervous processes estimation was realized according to the author's methodology created by E.P. Ilin in 1972 by means of the dynamics of hand movements tempo change. In terms of the research results interpretation we held factors analysis, which prevent the whole potential of physical culture means revelation at a higher educational establishment, including medical profile Universities, for an effective training of young specialists for their professional duties realization.
\end{abstract}

\section{Introduction}

Nowadays the course chosen by the Russian Federation for thorough society modernization provides higher education system modernization. It is necessary because of Russia integration into European educational space and the demands increase claimed on the quality of professional training in the specialists in accordance with the needs of modern labor market $[1,2]$.

Higher medical school is not an exception. One of the main components of higher medical education modernization is Federal state general education standard (FSGES). It provides educational strategies and technologies change in order to improve the quality and effectiveness of education in Russia [3].

Thus, the objectives of modern medical education, according to FSGES, should become an active, responsible, highly-professional, healthy individual upbringing and development. It is able to fulfill his professional duties successfully [4].

However, psychophysical and time research works analysis during recent years showed that the labor of the doctors of different specialties and age groups is accompanied by tiredness the main symptomatology of which is central nervous system functioning decrease. Such functions and indices as attention, speed of visual-motor and audio-motor

\footnotetext{
*Corresponding author: skiba87@mail.ru
} 
and others become worse among the doctors by the middle of the working day [5].

These facts characterize the work of central nervous system (CNS) and its steadiness. It is reflected in redistribution of an organism functions in terms of external factors. The level of a doctor's professionally necessary systems functioning decrease would lead to the quality of medical services decrease and then would form different chronic problems.

Taking into consideration all mentioned above one of the main objectives of a medical higher educational establishment is a purposeful CNS development, as one of the main components. It defines the degree of a specialist's readiness for a productive labor. The current state and degree of CNS development monitoring and estimation during the research is very urgent.

\section{Materials and Methods}

For functional state and working capacity of nervous system estimation among the future specialists of medical profile we used the complex (HSC) "NS-PsychoTest". It includes several specialized tests for the experimental study of nervous system and a person's psychological part. 50 students took part in the experiment (30 girls and 20 boys, who are from the main health group and study at the specialty "General Medicine" at Kazan State Medical University). Students were offered to fulfill warming-up before the test: for this purpose the respondent was fulfilling the instruction on the methodology during 5-10 seconds. Then, sitting at the table, the respondent took a special pencil into his right hand and during 30 seconds fulfilled finger-tip actions with maximal frequency on a special rubber "platform", which was connected with PC. During the test there was a verbal stimulation of the respondents ("Don't give up", "Work quicker").

The main feature of nervous processes estimation was realized according to the author's methodology created by E.P. Ilin in 1972 owing to the dynamics estimation of hand movements tempo [6].

\section{Results and Discussion}

In accordance with modern views concerning physiology an individual's life is provided by the range and close connection between all systems of a person's organism. The work of each functional system is vitally important and necessary for an organism. The main role in life support belongs to nervous system. Nervous system, the center of it is the brain, controls the work of all functional systems. The activity of it provides constant work of an organism. Owing to the constant work of nervous system there is different states change in the organism of a healthy person. They are optimal for the current situation and, as a result, the organism adapts to external conditions [7].

Thought nervous system fulfills identical functions in the work of any person's organism. Its specificity in each definite case is conditioned by individual features. They are usually inborn and don't change during a person's life. These features, discovered by a famous scientist I.P. Pavlov, are called the features of nervous processes [8].

For the features of nervous processes estimation we used such indices as: general number of finger-tip actions, the level of nervous system lability, as one of the main features of nervous system. It characterizes the speed of nervous processes stimulation and inhibition appearance and end. We also estimated endurance of nervous system. It is reflected in the ability to realize a long-term activity by an individual without its effectiveness decrease. Descriptive statistics of the results is presented by table 1 .

Table 1. The main features of nervous system estimation in medical students on the specialty "General Medicine" ( $\bar{x} \pm \sigma)$

\begin{tabular}{|c|c|c|}
\hline Indices & $\begin{array}{c}\text { Girls } \\
(\mathrm{n}=30)\end{array}$ & $\begin{array}{c}\text { Boys } \\
(\mathrm{n}=20)\end{array}$ \\
\hline
\end{tabular}


actions

\begin{tabular}{|c|c|c|}
\hline Lability level & $6,7 \pm 1,2$ & $7,1 \pm 2,2$ \\
\hline Endurance level & $8,0 \pm 1,5$ & $8,5 \pm 1,7$ \\
\hline
\end{tabular}

The received results help to come to the following conclusion: boys have more developed and steady nervous system. Mean value of general amount of finger-tip actions in boys was $224,2 \pm 42,7$ which is $9,9 \%$ higher than the indices in girls. This index ia the main criterion during nervous system liability level estimation and it is higher in boys $7,1 \pm 2,2$, than in girls $6,7 \pm 1,2$. Taking into account interpretational indices offered by E.P. Ilin the lability level of nervous processes can be characterized as «above the average» in boys and «average» in girls. Endurance level of nervous system was almost equal in the boys $8,5 \pm 1,7$ and in the girls $8,0 \pm 1,5$ and was characterized as «above the average».

Taking into account the received results we state nervous system indices decrease in medical students during their study at a higher educational establishment, as at the $1^{\text {st }}$ course students have "the average" and "above the average" indices of nervous system features and after graduation. When they start working, their nervous system can't stand the intensity of labor processes. It proves functional conditions of nervous system loss during studying at a higher educational establishment and the absence of professionally oriented physical training. It helps to minimize negative factors of influence during study and the future labor activity.

The existing situation with absence of valuable professionally oriented physical training for labor is normal in terms of modern legislative vertical. It provides multi-level system of different practical skills and professional competencies in terms of "Law on Education", declared in Federal State educational standards (FSES).

One of the main factors, which define the position of physical culture in the urgent FSES, is introduction of "elective" practical part of the discipline realization (328 hours). In the previous standard FSES of HPE 3 practical part had variable character and provided the opportunity to form corresponding with physical culture working program aims for an effective training of a specialist. In FSES of HPE 3+ practical part doesn't have this opportunity, as an elective form of lessons organization provides sports-oriented physical upbringing based on taking into consideration students' interests.

At the same time, most scientists have the opinion that "physical culture and sport elective disciplines" introduction into educational process restricts the opportunity of a purposeful training for professional activity. Physical culture, in the opinion of the authors, is the main discipline for a specialist of any sphere. On its "psychophysical base" professional activity would be formed and physical culture practical discipline projection claims demands on clearly formed and scientifically substantiated sequence of physical culture means use for professionally important physical qualities gaining [8].

As a result of the approach to the discipline, modern working programs formation at higher educational establishments, including medical profile, has its own individualpedagogical philosophy. As there are no clear recommendations concerning practical discipline projection, these approaches reflect individual interpretation of FSES items and personal preferences of physical culture department, soft and hardware support of them is restricted by the range of social-economic factors [9].

The range of mentioned above questions connected with modern physical upbringing organization, the absence of substantiated and professionally-oriented practical physical culture working programs leads to the fact that young specialists don't get demanded professionally important qualities and knowledge development in the sphere of professionally-applied physical training (PAPT) means use in professional activity and get into labor environment. Gained at a higher educational establishment health problems are combined with negative factors of the specialty, including those connected with the processes of nervous activity. In this case the doctor can't realize his or her professional duties at a high qualitative level. 
discipline from the point of view of standards, very often complete absence of educational and professional activity specificity understanding, leads to physical culture formalization. However, on physical culture depends the potential of any modern state.

\section{Conclusion}

The results of scientific-methodical literature and normative documents analysis helped to understand that modern physical upbringing at higher educational establishments, including medical profile, can't fully solve the set problems. This fact is proved by the results of the held experiment. It states that the indices of nervous processes features in medical students, who belong to the main health group and who study at the $1^{\text {st }}$ course of "General Medicine faculty" of Kazan State Medical University, are within the limits of physiological and age related norm. It means that one of the main problems, nervous system tiredness among doctors of different specialties and organism functions decrease during the working day, is gained one and proves the necessity to use special professionally-applied physical orientation means during training for labor activity, in the unit "Professionally-applied physical training" of educational discipline "Physical culture and sport elective disciplines".

\section{References}

1. A. Chugunov, A. Ilyasova Kazan Bulletin of Young Scientists 2(3), 121-126 (2019)

2. G. Fahrutdinova, I. Konovalov, Y. Boltikov, Eurasian Journal of Analytical Chemistry, 607-618 (2017)

3. A.S. Kuznetsov, Z.M. Kuznetsova, Russian Journal of Physical Education and Sport, 14(4), 5-7 (2019)

4. V. Rogozhin, V. Elagina Modern problems of science and education 6, (2017)

5. D. Kachanov, V. Manyushina, T. Solovykh, K. Chernova, G. Mkrtchan International Scientific-Research Magazine 11-1 (89), 130-134 (2019)

6. E. Ilin Psychophysiological Basis of Physical Upbringing and Sport, 5-15 (1972)

7. H. Ertan, I. Bayram, Comparative Kinesiology of the Human Body, 29-45 (2020)

8. M. Makarenko, V. Lizohub, Cherkasy University Bulletin: Biological Sciences Series 1, 49-58 (2019)

9. O. Kornev, I. Skiba International Magazine of the Applied Sciences and Technologies «Integral» 3, 540-544 (2019)

10. S. Bochkareva, T. Vysotskaya, A. Rostevanov Bulletin of Russian Economic University named after G.V. Plekhanov 4(94), $42-47$ (2017) 